\title{
Exploration of Digital Media Design Based on Painting Creation Ideas
}

\author{
Li Chen
}

\author{
Shenzhen Polytechnic, Shenzhen, 518055, China
}

Keywords: Painting creation. Ideas. Digital media design. Exploration

\begin{abstract}
With continuous progress and development of science and technology, China develops intensively in terms of new media, and digital media technology flourishes in recent years. Digital media technology shall not only rely on computer sciences and relevant content, but also combine painting creation well, so as to design more excellent works and cases and develop digital media technology continuously. This paper explores digital media design based on painting creation ideas and analyzes the influence of painting creation on digital media design.
\end{abstract}

\section{Introduction}

With continuous development of information technology and multimedia technology, digital media technology has been known well by people gradually, and digital media has become a very hot major which designs and creates through computer technology. The so-called digital media technology contains very extensive content, including webpage making, game design, and creation of animation effects etc, covering lots of majors and is strongly professional and comprehensive. Facing growing progress of information technology, we shall clearly realize the rapid development trend of digital media technology, which not only relies on computer operation but also involves lots of professional content, a very important part of which is painting creation. It can also be said that digital media technology not only needs people with computer skills, but also involves people with art skills and strong aesthetics.

At present, lots of Chinese colleges have set up the course of digital media technology, and generally focus on students' computer training in most cases and mainly require students to understand and be familiar with computer software in classes, while ignoring a very important course related to it, i.e. painting teaching. Some colleges set some painting courses only in the freshman year, but implement according to traditional art teaching with main content of drawings, sketches, and some color matching courses, and fail to teach and explain in strict accordance with requirements of digital media technology course. Therefore, both cannot be combined organically, let alone training students well to be professional talents in digital media technology.

Of course, Chinese colleges still have many problems in these aspects, and this paper will highlight and list some problems below.

\section{Current problems of Chinese colleges while setting digital media technology major}

\section{Overreliance on computer operation and computer software}

Many colleges believe unilaterally that digital media technology is the product of rapid development of information and continuous progress of new media, and is mainly inseparable from the support and assistance of computers. When setting up courses, many colleges arrange mostly computer theory courses, computer operation courses, and basic learning of computer software and digital media creation software related to computer for students majoring in digital media design, and thus every class is closely related to computer. As a result, on the one hand, students' knowledge becomes boring operation, and on the other hand, they learn basically nothing about other majors, and could not learn other courses related to their major. Indeed, we cannot deny that excellent professional skills and computer operation skills are decisive factors of being competent for this job for students majoring in digital media design. However, we shall clearly know that we are not training mechanic talents but innovative talents, and focus on creative design through digital media 
technology. So, simply learning computer operation cannot satisfy demands of digital media design for students, let alone meeting social requirements of such talents.

\section{No concentration on training students' artistic creativity}

Digital media design focuses on both technology and creativity. Training and developing of artistic creativity are very important for students majoring in creative design. However, many Chinese colleges with this major pay little attention to training students' artistic creativity. For example, when teachers give a topic for students to create and practice through 3D technology, lots of students feel helpless, and some would "search on Baidu" for some pictures and content to complete assignment given by teachers. Obviously, this does not comply with requirements of digital media design. Let's firstly put the infringement of intellectual property rights aside, training of students' creativity is not fully reflected. Students plagiarize other's work for their own assignment, and have not imagination or creativity.

\section{Efforts shall be made from the following aspects to better solve these problems}

In recent years, many Chinese colleges have set up digital media design major. Shenzhen Polytechnic is one of higher education institutions that are the first to set up similar majors and have achieved very good teaching effects. Among these majors, multimedia, animation, video and games etc become excellent ones in China, and a large number of digital media design workers are trained for China especially Shenzhen. With specific practices of School of Animation, Shenzhen Polytechnic on training digital media designers with painting creation ideas, this paper explains and analyzes below.

\section{Pay more attention to and emphasize learning of sketches and freehand sketching}

Sketches and freehand sketching are parts of art painting, and are also very important means for art teaching and digital media technology teaching. It's easy to find that some elder art teachers still paint by sketches and freehand sketching in many colleges, and such traditional painting methods are very conducive to giving play to creativity. Teachers shall teach such traditional painting habits to students, so that students would tend to sketches and freehand sketching, rather than simply relying on computers. Many years of surveys and data analysis indicate that teachers would ask students to hand in freehand sketching and sketches regularly. Most students use several sketchbooks each semester. By browsing sketchbooks of each student, it can be found that most students would choose to facsimile and paint content or objects that they are interested in at the beginning, and would gradually have new creation with these objects as carriers, and each painting reflects each student's different creating styles and personalities, which are important reflection of students' progress.

When teachers ask students to make creative design by 3D technology, students would not have to turn on computers to plagiarize by search engine, but open their sketchbooks and see whether there is content that could stimulate their creativity, so as to gain inspiration from assignment they have completed before. Such teaching method would help students get rid of computers to a great extent, and stimulate more inspiration in digital media design, instead of plagiarizing others' works or seeking inspiration from others' works.

\section{Establish studios and workshops for students to paint and exchange}

By establishing studios and workshops, students could paint, practice and exchange more conveniently. Usually, on weekends, organize students together and arrange some courses related to their majors but could not be learnt in classroom. For example, teachers could arrange students to have courses related to films, photography, film clips and post-production on weekends, and introduce relevant knowledge to lay a foundation for development and learning of digital media technology. Of course, perhaps it will not help too much for digital media design or have direct relations by simply learning these courses, and thus we shall associate organically these courses with professional content that we learn usually, so that students could master knowledge and obtain unexpected gains.

Besides arranging courses for students, we could also hold some meaningful extracurricular activities, such as collective painting, video analysis and exhibition of photography works, all of 
which train and improve students' aesthetic ability. Being exposed to such works of art, more creation inspiration shall be provided for future digital media creation. Students would find content they are interested in through rich courses and activities on weekends, so as to expand their majors, learn other professional knowledge and enrich themselves, and also accumulate more materials for digital media design.

Some colleges establish studios and workshops, which play a very profound role in students' learning of professional knowledge and enriching extracurricular activities. Lots of students would put forward some questions related to computer operation to teachers in classes on weekends, and would design some little games.

\section{Emphasize training compound talents of digital art based on painting creation}

In colleges with digital media professional teaching, most teachers do not have very comprehensive knowledge and ability. Teachers, who focus on computer teaching, may have very deep knowledge and practical knowledge in terms of understanding computer operation, computer software and knowledge, and can impart knowledge to students very well. However, they may be relatively weak in terms of training painting basics and painting creation ability; while those who focus on painting ability, painting creation and learning may have very unique views on colors and picture composition, but would not be that proficient in computer operation. Thus, teachers are required to communicate well with each other, combine advantages of both, give play to their advantages and strengths, train students' computer operation ability and painting ability, and never make students ignore practice and emphasis of computer operation during painting. Meanwhile, training of students' overall qualities shall be highlighted. In current higher vocational colleges, Shenzhen Polytechnic is the first that put forward three concepts of "cultural education", "compound education" and "cooperative education", which provide a good environment for us to train adaptive digital art compound talents. These three concepts can better help students gain comprehensive knowledge and skills, ensure students to learn more knowledge to a maximum extent and lay a comprehensive and solid cultural and artistic foundation, and make efforts to train digital media design talents that the society needs.

\section{Conclusions}

With continuous development of science and technology and constant progress of new media industry, as a new hot major in contemporary era, digital media design shall be attached enough importance to. Current digital media design is not very developed, and generally focuses on training students' computer ability, while ignoring the help and influence of painting creation ideas on digital media design. So, we shall solve this issue fundamentally, and shall try to let students learn all courses and knowledge related to the major in terms of course arrangement in colleges, rather than simply defining digital media design as computer operation and familiarity with computer software. Therefore, training of students' painting ability and development of painting courses shall be solved urgently. Colleges shall fully carry out painting courses, combine course content with students' major organically, stimulate students' creation inspiration constantly, and thus create creative digital media design cases, and train students to be digital media designers that adapt to the development of the times and meet social demands.

\section{References}

[1] Hao Zhenhua: Exploration of Teaching Positioning of Digital Media Design Course, China Education Innovation Herald, 2011, 13: 168-169.

[2] Zhou Yongxing: Importance of Painting Creation for Digital Media Design, Art, 2012, 01: 99.

[3] Lv Ruimin: Study on Key Technologies and Systematic Design of New Media Painting [D]. Zhejiang University, 2012. 
[4] Li Sida: Exploration of the Teaching Mode of Digital Media Art, Journal of Beijing University of Posts and Telecommunications (Social Sciences Edition), 2010, 04: 1-5+24.

[5] Li Aihong: On Development Trend of Digital Media Design Major, The Art and Crafts of Zhejiang Province, 2006, 01: 98-99.

[6] Zhang Yunfeng: Digital Media Realization of Text Graphic Design [D]. Shandong University, 2012.

[7] Yang Haosheng: Hou Yanhua. Digital Media Major: Current Status, Problems \& Reflection, Journal of Beijing Radio and TV University, 2008, 04: 35-37. 